\title{
Characteristics of carbon dioxide adsorption on $\beta$-cyclodextrin/cellulose composite material
}

\author{
Tianxiang Guo ${ }^{1 a}$, Nan Ma ${ }^{1 b}$, Simeng Chen ${ }^{1}$, Baixin Wang ${ }^{1}$, Lian \\ $\mathrm{Su}^{1}$, HuiningXiao $^{2}$ \\ ${ }^{1}$ Department of Environmental Science and Engineering, North China Electric Power University, \\ Baoding 071003, China
}

${ }^{2}$ Department of Chemical Engineering, University of New Brunswick, Fredericton E3B 5A3, Canada a99623935@qq.com, b1322196994@qq.com

\begin{abstract}
Keywords: $\mathrm{CO}_{2}$ adsorption; $\beta$-cyclodextrin; cellulose; adsorption capacity; selectivity.
Abstract: The work focused on the preparation and characterization of porous composite material as novel adsorbent towards $\mathrm{CO}_{2}$. The porous composite material was synthesized by cross-linking of cellulose and $\beta$-cyclodextrin with epichlorohydrin (EPI). Then the adsorption characteristics of carbon dioxide on the porous composite material, such as adsorption capacity and selectivity were experimentally investigated. The experimental results showed pulp cellulose in selected types of cellulose was more suitable for the synthesis of $\mathrm{CO}_{2}$ composite adsorbent. Meanwhile, the analysis from BET and FTIR indicated that the $\beta$-cyclodextrin was grafted pulp cellulose by epichlorohydrin. The grafted cellulose led to the surface area and pore size of $\beta$-cyclodextrin increased by 3.78 and 2.96 times. Compared with $\mathrm{CO}_{2}$ adsorption capacity of $3.186 \mathrm{~cm}^{3} / \mathrm{g}$ on the $\beta$-cyclodextrin, EPI/PC-CD composite exhibited a higher capacity of $\mathrm{CO}_{2}$ adsorption $\left(8.613 \mathrm{~cm}^{3} / \mathrm{g}\right)$ at $298 \mathrm{~K}$ and $1 \mathrm{bar}$, accompanying an endothermic process and the isosteric heat between 72 and $78 \mathrm{~kJ} / \mathrm{mol}$. Moreover, the adsorption selectivity of $\mathrm{CO}_{2}$ over $\mathrm{N}_{2}$ retained above 13 at $298 \mathrm{~K}$.
\end{abstract}

\section{Introduction}

Global warming resulted from the emission of greenhouse gases has received much attention recently. Various $\mathrm{CO}_{2}$ capture technologies, such as chemical absorption, adsorption and membrane, have been exploited to reduce $\mathrm{CO}_{2}$ emissions [1]. However, the conventional absorption processes such as alkanolamine aqueous solutions still possess some drawbacks, e.g, high equipment corrosion rate, high energy consumption in regeneration; whereas the membrane technologies have not yet been matured for disposing huge amount of flue gas due to the existence of significant mass transfer limitations. As a result, adsorption processes are well received as the effective approaches to overcome these inherent problems by using some high-efficient adsorbents, such as activated carbon[2-4], 13X molecular sieve [5,6] and various other silicate materials[7,8].

The investigations of $\mathrm{CO}_{2}$ encapsulation and complexation with cyclodextrins have indicated that $\beta$-cyclodextrin could form cyclodextrin based nanosponges with inclusion of $\mathrm{CO}_{2}$. However, the literatures related to $\mathrm{CO}_{2}$ capture of composite from $\beta$-cyclodextrin through cross-linking[9] for gaseous phase catalytic synthesis and the reduction of $\mathrm{CO}_{2}$ emission are very limited. Moreover, those derivatives were restricted in their application. Thereby, it is necessary to synthesize eco-friendly $\mathrm{CO}_{2}$ adsorbent based on $\beta$-cyclodextrin with less use of those poisonous chemicals.

Recently, cellulose has drawn increasing attention as reinforcing agents in polymer composites[10,11] due to biodegradable, easy obtaining and little investing. Although the literature related to $\mathrm{CO}_{2}$ inclusion by cellulose for gaseous phase catalytic synthesis and the reduction of $\mathrm{CO}_{2}$ emission $[12,13]$ have been limited reported, the application of porous composite material of cellulose/ $\beta$-cyclodextrin for $\mathrm{CO}_{2}$ uptake still remains available for exploration. In order to prepare the porous composite material as $\mathrm{CO}_{2}$ adsorbent, epichlorohydrin (EPI) was used as a coupling agent to achieve the cross-linking of cellulose and $\beta$-cyclodextrin. Meanwhile, the porous composite material was characterized by Brunauer-Emmett-Teller(BET) theory, Fourier Transform 
Infrared (FTIR) spectra, Then its performances of gas adsorption, such as adsorption capacity of $\mathrm{CO}_{2}$ and selectivity of $\mathrm{CO}_{2}$ over $\mathrm{N}_{2}$ were experimentally investigated.

\section{Materials and methods}

\section{Materials}

Pulp cellulose was obtained from Money Printing Plant in Baoding. Microcrystalline cellulose (MCC, 99\% purity), $\beta$-cyclodextrin ( $\beta$-CD) powder (98\% purity) and epichlorohydrin (EPI) were purchased from Shanghai Aladdin Biochemical Polytron Technologies Inc. Ethanol(anhydrous), sodium hydroxide and urea came from Tianjin XingFu Technology Development Co., Ltd. All these chemicals were used as received without further purification.

\subsection{Synthesis and characteristics of porous adsorbent}

The porous adsorbents were prepared by the cross-linking of cellulose and $\beta$-cyclodextrin $(\beta-C D)$ with EPI. Firstly, the cellulose was dissolved in a flask $(100 \mathrm{ml})$ with the solution $(48 \mathrm{ml})$ of sodium hydroxide $(3.5 \% \mathrm{w} / \mathrm{w})$ and urea $(6 \% \mathrm{w} / \mathrm{w})$ followed by the addition of $\beta$-cyclodextrin $(\beta-\mathrm{CD})$ and stirring until the system was well mixed. Then some amount of EPI was gradually and slowly added to this system in $20 \mathrm{~min}$. The solution was kept at certain temperature for $4 \mathrm{hrs}$, then precipitated with $50 \mathrm{ml}$ of ethanol. The precipitate was treated by washing with distilled water/ethanol, product was obtained through filtering and drying under vacuum overnight.

The adsorption isotherms of $\mathrm{CO}_{2}$ at $298 \mathrm{~K}$ and $273 \mathrm{~K}$ was experimentally obtained based on volumetric gas adsorption method. The as-prepared porous material, $\mathrm{PC}$ and $\beta-\mathrm{CD}$ were recorded by using Tensor II FTIR spectroscopy (BRUKER Technologies) associated with diffuse reflectance accessory (PURGE Technologies). The BET surface areas of as-prepared porous Material and $\beta$-CD were analyzed based on volumetric gas adsorption method $\left(P / P_{0}=0.05 \sim 0.35\right)$ with the measurement using JW-BK122W static nitrogen adsorption analyzer(JWGB Sci\& Tech Co. Ltd , Beijing) at $77 \mathrm{~K}$.Then their pore size distributions were obtained based on $\mathrm{BJH}$ and $\mathrm{HK}$ methods.

\section{Results and discussion}

\section{Influence of cellulose type on $\mathrm{CO}_{2}$ adsorption}

In our synthesis, Epichlorohydrin was used to prepare the porous adsorbents through the cross-lingking of $\beta$-cyclodextrin with various cellulose, which were respectively referred as EPI/PC-CD for pulp cellulose, EPI/MCC-CD for microcrystalline cellulose. Then $\mathrm{CO}_{2}$ adsorption characteristics of these composite adsorbents at $298 \mathrm{~K}$ are presented in Figure 1. As presented in Figure 1, the capacities of $\mathrm{CO}_{2}$ adsorption on these composite adsorbents increased with increasing gas pressure of $\mathrm{CO}_{2}$, which were $3.342 \mathrm{~cm}^{3} / \mathrm{g}$ for EPI/MCC-CD, $8.613 \mathrm{~cm}^{3} / \mathrm{g}$ for EPI/PC-CD when the gas pressure was 1 bar. The composite adsorbent EPI/PC-CD exhibited higher capacity of $\mathrm{CO}_{2}$ adsorption, indicating that cellulose type had a significant effect on $\mathrm{CO}_{2}$ adsorption performance and pulp cellulose was suitable for $\beta$-cyclodextrin to prepare the porous material as $\mathrm{CO}_{2}$ adsorbent.

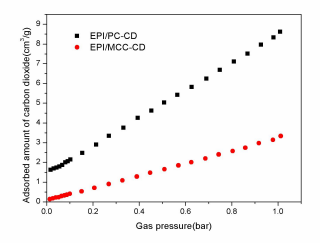

Figure. $1 \mathrm{CO}_{2}$ adsorption on as-prepared adsorbents from different cellulose

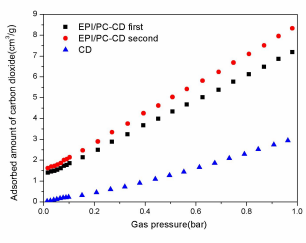

Figure. 2 Capacity change of $\mathrm{CO}_{2}$ adsorption based on parallel tests

\section{Influence of cross-linking parameters on $\mathrm{CO}_{2}$ adsorption}

In consideration of obviously higher capacity of $\mathrm{CO}_{2}$ adsorption on EPI/PC-CD than EPI/MCC-C $\mathrm{D}$, the effects of cross-linking parameters such as cross-linking temperature, mass ratio of $\beta$-CD to $\mathrm{PC}$ and EPI dosage, on $\mathrm{CO}_{2}$ adsorption of EPI/PC-CD were experimentally investigated based on orthogonal method and the results are listed in Table 1. As seen from Table 1, the capacity of $\mathrm{CO}_{2}$ adsorption on the porous composite adsorbent EPI/PC-CD varied in the range of 2.054 to $8.613 \mathrm{~cm}^{3} / \mathrm{g}$. The EPI dosage exhibited the most significant effect on $\mathrm{CO}_{2}$ adsorption of EPI/PC-CD, 
followed by mass ratio of $\beta-\mathrm{CD}$ to $\mathrm{PC}$ and cross-linking temperature. This indicated that EPI dosage was the key parameter in the synthesis of EPI/PC-CD and the $\mathrm{CO}_{2}$ adsorption performance of EPI/PC-CD could be improved by modifying these cross-linking parameters. The optimum conditions(denoted as $\beta$-CD/PC-1-4-333) determined by analysis of orthogonal method included that the synthesis temperature was $333 \mathrm{~K}$, mass ratio of $\beta-\mathrm{CD}$ to PC was $1: 1$ and the EPI Dosage was $4 \mathrm{ml} /(1 \mathrm{~g} \beta-\mathrm{CD})$.

Two parallel samples based on above optimum conditions was tested, and the results of $\mathrm{CO}_{2}$ adsorption are shown in Figure 2. As seen from Figure 2, the capacity of $\mathrm{CO}_{2}$ adsorption at 1 bar and $298 \mathrm{~K}$ varied in the range of 7.427 to $8.613 \mathrm{~cm}^{3} / \mathrm{g}$. Compared with $\mathrm{CO}_{2}$ adsorption capacity of $3.186 \mathrm{~cm}^{3} / \mathrm{g}$ on pure $\beta-\mathrm{CD}$ without the cross-linking of $\mathrm{PC}$, the porous composite adsorbent EPI/PC-CD with the cross-linking of $\mathrm{PC}$ exhibited a higher capacity of $\mathrm{CO}_{2}$ adsorption $\left(7.427-8.613 \mathrm{~cm}^{3} / \mathrm{g}\right)$ at 1 bar and $298 \mathrm{~K}$.

Table 1 Analysis of orthogonal method for $\mathrm{CO}_{2}$ adsorption

\begin{tabular}{|c|c|c|c|c|}
\hline sample & $\begin{array}{c}\beta-\mathrm{CD} / \mathrm{PC} \\
\text { mass ratio }\end{array}$ & $\begin{array}{c}\mathrm{EPI} \\
\text { dosage(ml) }\end{array}$ & $\begin{array}{c}\text { Cross-linking } \\
\text { temperature(K) }\end{array}$ & $\begin{array}{c}\mathrm{CO}_{2} \\
\text { uptake(cm } / \mathrm{g})\end{array}$ \\
\hline$\beta$-CD/PC-1-2-313 & 1 & 2 & 313 & 4.573 \\
\hline$\beta$-CD/PC-1-4-333 & 1 & 4 & 333 & 8.613 \\
\hline$\beta$-CD/PC-1-6-353 & 1 & 6 & 353 & 2.550 \\
\hline$\beta-\mathrm{CD} / \mathrm{PC}-0.5-2-333$ & 0.5 & 2 & 333 & 3.196 \\
\hline$\beta$-CD/PC-0.5-4-353 & 0.5 & 4 & 353 & 3.054 \\
\hline$\beta-\mathrm{CD} / \mathrm{PC}-0.5-6-313$ & 0.5 & 6 & 313 & 3.655 \\
\hline$\beta-\mathrm{CD} / \mathrm{PC}-2-2-353$ & 2 & 2 & 353 & 2.587 \\
\hline$\beta-\mathrm{CD} / \mathrm{PC}-2-4-313$ & 2 & 4 & 313 & 3.914 \\
\hline$\beta-\mathrm{CD} / \mathrm{PC}-2-6-333$ & 2 & 6 & 333 & 2.054 \\
\hline $\mathrm{k} 1$ & 5.245 & 3.452 & 4.047 & \\
\hline $\mathrm{k} 2$ & 3.302 & 5.194 & 4.621 & \\
\hline $\mathrm{k} 3$ & 2.852 & 2.753 & 2.730 & \\
\hline $\mathrm{Delta}$ & 2.394 & 2.441 & 1.891 & \\
\hline & 2 & 1 & 3 & \\
\hline & & \multicolumn{3}{l}{} \\
\hline
\end{tabular}

\section{Adsorbent characteristics}

The tests of BET of $\beta$-cyclodextrin aggregates and solid acid derivative were conducted to study surface area and pore structures. $\beta-C D$ exhibited only $5.34 \mathrm{~m}^{2} / \mathrm{g}$ of specific surface area and $1.03 \times 10^{-2} \mathrm{~cm}^{3} / \mathrm{g}$ of pore volume with a mean pore size of $34 \mathrm{~nm}$. In contrast, the EPI/PC-CD obtained after the cross-linking PC by EPI exhibited $20.22 \mathrm{~m}^{2} / \mathrm{g}$ of specific surface area and $3.05 \times 10^{-2} \mathrm{~cm}^{3} / \mathrm{g}$ of pore volume, which were 3.78 and 2.96 times higher than native $\beta$-cyclodextrin aggregates. Meanwhile, the mean pore size of EPI/PC-CD decreased into $30 \mathrm{~nm}$. The higher specific surface area and pore volume with decreased mean pore size of EPI/PC-CD, compared with $\beta$-cyclodextrin aggregates, indicated that the crosslinking PC by EPI led to the formation of porous structure of the composite.

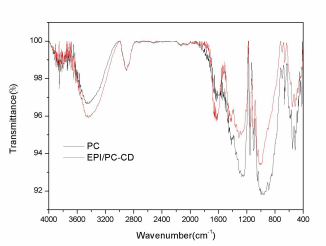

Figure 3. FTIR spectra of pulp cellulose and EPI/PC-CD composite

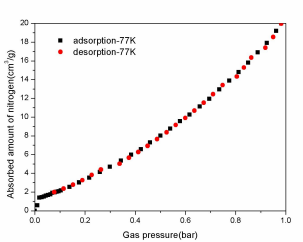

Figure 4. Isotherms of $\mathrm{N}_{2}$ adsorption and desorption at $77 \mathrm{~K}$

Meanwhile, those functional groups on the surface of solid acid derivative were demonstrated by the results FTIR spectra of pulp cellulose and EPI/PC-CD composite presented in Figure 3. As seen in Figure 3, the peak type and wave number of the infrared spectra of PC and EPI/PC-CD composite are similar because $\beta$-cyclodextrin aggregates and pulp cellulose owned similar groups. Compared pulp cellulose, the intensities of the peaks between 3450 and $3500 \mathrm{~cm}^{-1}$ due to $\mathrm{O}-\mathrm{H}$ 
stretching vibration and between 1600 and $1700 \mathrm{~cm}^{-1}$ due to the $\mathrm{O}-\mathrm{H}$ bending vibration were also obviously increased. In addition, the intensities of peaks between 2850 and $2900 \mathrm{~cm}^{-1}$ due to C-H stretching vibration unchanged, Finally, the intensities of peaks at $1300 \mathrm{~cm}^{-1}$ due to C-O stretching vibration was shifted, which due to the crosslinking. In order to study the gas adsorption properties of the gas adsorbents synthesized in this experiment, we have measured the adsorption and desorption capacity of nitrogen at $77 \mathrm{~K}$. As seen from Figure 4, the adsorption curve of $\mathrm{N}_{2}$ was well coincided with desorption curve, indicating that $\mathrm{N}_{2}$ adsorption was almost a physisorption process.

\section{Influence of temperature and pressure on $\mathrm{CO}_{2}$ adsorption}

In order to investigate the characteristics of gas adsorption on the porous composite material EPI/PC-CD, $\mathrm{CO}_{2}$ adsorption and desorption at 273 and $298 \mathrm{~K}$ was experimentally measured within the $\mathrm{CO}_{2}$ pressure range of 0-1bar; and the results are shown in Figure 5. As shown in Figure 5(a), the capacity of $\mathrm{CO}_{2}$ adsorption on the porous composite adsorbent increased with the increase of $\mathrm{CO}_{2}$ pressure and temperature. For instance, the capacities of $\mathrm{CO}_{2}$ adsorption at $298 \mathrm{~K}$ were significantly affected by $\mathrm{CO}_{2}$ pressure, which were $5.030 \mathrm{~cm}^{3} / \mathrm{g}$ at $0.5 \mathrm{bar}$ and $8.613 \mathrm{~cm}^{3} / \mathrm{g}$ at $1 \mathrm{bar}$, respectively. The capacity of $\mathrm{CO}_{2}$ adsorption at 0.5 bar declined to $5.030 \mathrm{~cm}^{3} / \mathrm{g}$ from $1.362 \mathrm{~cm}^{3} / \mathrm{g}$ with increasing adsorption temperature from $298 \mathrm{~K}$ to $273 \mathrm{~K}$, indicating that $\mathrm{CO}_{2}$ adsorption on as-prepared composite adsorbent was an endothermic process and high $\mathrm{CO}_{2}$ adsorption capacity could be achieved at high temperature. According to the method described in the literature[14,15], the isosteric heat of $\mathrm{CO}_{2}$ adsorption in Figure 5(b) were between 72 and $78 \mathrm{~kJ} / \mathrm{mol}$.

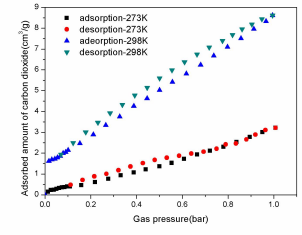

(a)

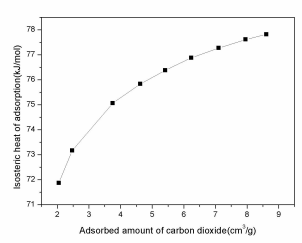

(b)

Figure 5. Isotherms(a) and isosteric heat(b)

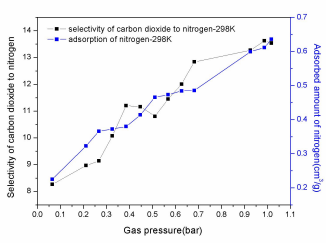

Figure 6 Adsorption selectivity of $\mathrm{CO}_{2}$ over $\mathrm{N}_{2}$ at $298 \mathrm{~K}$

Selectivity

The selectivity of $\mathrm{CO}_{2}$ adsorption is very important for the porous composite adsorbent EPI/PC-CD in its application of gaseous phase catalytic synthesis and gas adsorption. Therefore, the behavior of $\mathrm{N}_{2}$ adsorption was also experimentally investigated and the related results are shown in Figure 6. As seen from Figure 6, the capacity of $\mathrm{N}_{2}$ adsorption increased slightly with the increase of gas pressure below 1 bar and retained below $0.853 \mathrm{~cm}^{3} / \mathrm{g}$. For instance, when gas pressure increased from 0.4 bar to $0.6 \mathrm{bar}$, the capacity of $\mathrm{N}_{2}$ adsorption at $298 \mathrm{~K}$ only increased to $0.379 \mathrm{~cm}^{3} / \mathrm{g}$ from $0.484 \mathrm{~cm}^{3} / \mathrm{g}$, which were much less than that of $\mathrm{CO}_{2}$ adsorption. For the porous composite adsorbent EPI/PC-CD, the adsorbed molar ratios of $\mathrm{CO}_{2}$ to $\mathrm{N}_{2}$ were above 13 at $298 \mathrm{~K}$, indicating that high adsorption selectivity of $\mathrm{CO}_{2}$ over $\mathrm{N}_{2}$ could be achieved.

\section{Conclusion}

A porous composite material derived from pulp cellulose and $\beta$-cyclodextrin was successfully prepared and used as $\mathrm{CO}_{2}$ adsorbent. The adsorption properties of $\mathrm{CO}_{2}$ were experimentally investigated at different temperatures and gas pressures. In addition, the characteristics of the adsorbent were revealed with the analysis of BET and FTIR. The capacity of $\mathrm{CO}_{2}$ adsorption at $298 \mathrm{~K}$ was $8.613 \mathrm{~cm}^{3} / \mathrm{g}$ at $1 \mathrm{bar}$ and adsorption selectivity of $\mathrm{CO}_{2}$ over $\mathrm{N}_{2}$ reached above 13 , indicating the as-prepared porous composite material could be used as $\mathrm{CO}_{2}$ adsorbent.

\section{Acknowledgments}

The research is supported by Beijing Municipal Natural Science Foundation (Grant\#:2184123), the Foudamental Research Funds for the Central Universities in China(Grant\#:2015ZD23), National 
Undergraduate Training Programs for Innovation and Entrepreneurship(Grant\#:201710054194) and NSF China (Grant\#:51379077 and 21466005) and NSERC Canada.

\section{References}

[1] C.H. Yu, C.H. Huang and C.S. Tan: Aerosol. Air. Qual. Res. Forum Vol. 12(2012), pp. 745-769

[2] N.P. Wickramaratne and M. Jaroniec: ACS Appl. Mater. Interfaces. Forum Vol. 5(2013), pp. 1849-1855

[3] B. Guo, L. Chang and K. Xie: J. Nat. Gas. Chem. Forum Vol. 15(2006), pp. 223-229

[4] R.V. Siriwardane, M.S. Shen, E.P. Fisher and J.A. Poston: Energ. Fuel. Poston, Forum Vol. 15(2001), pp. 279-284

[5] R.V. Siriwardane, M.S. Shen, E.P. Fisher and J. Losch: Energ. Fuel. Forum Vol. 19(2005), pp. 1153-1159

[6] M.M. Tomadakis, H.H. Heck, M.E. Jubran and K. Al-Harthi Sep. Sci. Technol. Forum Vol. 46(2011), pp. 428-433

[7] F. Rezaei, R.P. Lively, Y. Labreche and G. Chen: ACS Appl. Mater. Interfaces. Forum Vol. 5(2013), pp.3921-3931

[8] L.M.U. Thi, S.Y. Lee and S.J. Park: Int. J. Hydrogen Energy. Forum Vol. 39(2014), pp.12340-12346

[9] W. Wenhai, D. Jiang, W. Tin and T. Haiyang: Tetrahedron. Forum Vol. 74(2018),pp. 360-365

[10] M.S. Peresin, A.H. Vesterinen and O.J. Rojas: biomacromolecules. Forum Vol. 11(2010), pp. 2471-2477

[11] J.O. Zoppe, M.S. Zoppe and R.A. Habibi: ACS Appl. Mater. Interfaces. Forum Vol. 1(2009), pp. 1996-2004

[12] H. Liu, Y. Li, H. Wu and J. Liu: Chin. J. Catal. Forum Vol. 36(2015), pp. 283-289

[13] T.L. Neoh, H. Yoshii and T. Furuta: J. Incl. Phenom. Macrocycl Chem. Forum Vol. 56(2006), pp. $125-133$

[14] G. Tianxiang, A.H. Bedane and P. Yuanfeng: Mater. Let. Forum Vol.189(2017), pp. 114-117

[15] C.F. Cogswell, H Jiang, J. Ramberger and D. Accetta: Langmuir Forum Vol.31(2015), pp. 4534-4541 